\title{
BIOSKOP DALAM RUMAH (MEDIATISASI BIOSKOP)
}

\author{
Fina Zahra \\ Program Studi Komunikasi dan Penyiaran Islam, Fakultas Ushuluddin dan Dakwah, IAIN Kediri \\ Jl. Sunan Ampel No.7, Ngronggo, Kec. Kota Kediri, Kota Kediri, Jawa Timur 64127 \\ E-mail: zahra92.fina@gmail.com
}

\begin{abstract}
In-Home Cinema (Mediatization of Cinema). The current pandemic is driving many changes, including in the way to enjoy entertainment, which is now mostly online. One of the newest online video entertainment service providers is bioskoponline.com. As the name suggests, this site adopts conventional cinema services, but provides exclusive Indonesian films that can be accessed by users who have purchased tickets for 48 hours. Although enjoying movies online is nothing new, the concept that bioskoponline.com carries in the midst of this pandemic condition provides new experiences for its users and is interesting to research. The results of the study are expected to provide an overview of the changes that occur now and in the future due to changes in the media for watching movies, so that concrete steps can be taken in relation to this. In this research report, I use an intrinsic case study as a method to explain this new media-driven mediation. The results showed that as a new media, bioskoponline.com not only changed the vehicle for watching movies in the cinema into a digital version, but also provided several new experiences to its users. bioskoponline.com encourages new ways to enjoy films, as well as encourages new discourse about Indonesian films, especially regarding piracy which is a crucial issue for the film industry. Meanwhile, considering that cinemas will resume, it is advisable that bioskoponline.com improve its media technology and community base.
\end{abstract}

Keywords: mediatization, cinema, film, piracy, discourse.

\section{ABSTRAK}

Pagebluk yang tengah melanda mendorong banyak perubahan, termasuk dalam cara menikmati hiburan yang kini sebagian besar beralih secara daring. Salah satu penyedia layanan hiburan berupa video secara daring yang terbaru adalah bioskoponline.com. Sebagaimana namanya, situs tersebut mengadopsi layanan bioskop konvensional, namun dengan menyediakan film-film Indonesia eksklusif yang dapat diakses oleh pengguna yang telah membeli tiket selama 48 jam. Meskipun menikmati film secara daring bukan hal baru, tetapi konsep yang diusung bioskoponline.com di tengah kondisi pagebluk ini memberi pengalaman baru bagi penggunanya dan menarik untuk diteliti. Hasil penelitian diharapkan dapat memberi gambaran tentang perubahan yang terjadi saat ini dan yang akan datang karena perubahan pada media untuk menonton film, sehingga dapat dilakukan langkah konkret terkait hal tersebut. Dalam laporan penelitian ini, saya menggunakan intrinsic case study sebagai metode untuk menjelaskan mediatisasi yang didorong oleh media baru ini. Hasil penelitian menunjukkan bahwa sebagai media baru, bioskoponline.com bukan sekadar mengalih wahana kegiatan menonton film di bioskop ke dalam versi digital, melainkan juga memberikan beberapa pengalaman baru kepada penggunanya. bioskoponline.com mendorong adanya cara-cara baru dalam menikmati film, sekaligus mendorong wacana baru tentang film Indonesia, terutama terkait pembajakan yang merupakan isu krusial industri film. Sementara itu mengingat bahwa bioskop konvensional akan kembali beroperasi, disarankan bioskoponline.com untuk menyempurnakan teknologi medianya dan basis komunitasnya.

Kata kunci: mediatisasi, bioskop, film, pembajakan, wacana. 


\section{PENDAHULUAN}

Pagebluk yang tengah melanda mempengaruhi kehidupan di seluruh dunia dalam berbagai aspek, salah satunya adalah hiburan seperti menonton film secara daring. Menonton film secara daring sebenarnya bukan hal baru, tetapi karena selama pagebluk ini bioskop-bioskop terpaksa tutup, sementara masyarakat tetap membutuhkan hiburan seperti menonton film, maka jumlah akses terhadap film secara daring meningkat pesat ${ }^{1}$.

Di tengah pagebluk dan penetrasi internet di Indonesia yang makin luas, bioskoponline.com hadir dengan menawarkan "menonton film Indonesia berkualitas yang legal dan terjangkau". Sebelumnya sudah ada beberapa layanan video daring yang menawarkan akses legal dalam menonton film, tetapi sistemnya berlangganan. Memang bila dihitung-hitung menjadi lebih murah, tetapi tidak ekonomis. Sementara itu, bioskoponline.com menawarkan sistem pembelian per tiket sekitar Rp 5.000-10.000 selama 48 jam setelah pembelian. Hal ini mengadopsi sistem pembelian tiket untuk menonton film di bioskop (mencerminkan namanya sebagai bioskop online) dan bertujuan mencegah pembajakan. Hal lainnya adalah bioskoponline.com hanya bisa diakses

\footnotetext{
${ }^{1}$ Julian, M. (2020). McKinsey: Begini Kebiasaan Baru Konsumen yang Perlu Diantisipasi Perusahaan. Diakses melalui
}

melalui komputer, meskipun sejak beberapa hari terakhir tulisan ini dipresentasikan di Seminar Virtual FSMR 2020 bioskoponline.com sudah bisa diakses melalui browser di smartphone. Hal ini merupakan salah satu yang membedakannya dengan layanan video daring lain yang seperti Klik Film, yang sudah ada aplikasinya di smartphone. Selain itu, bioskoponline.com menawarkan film-film Indonesia yang sudah memenangkan berbagai penghargaan baik nasional maupun internasional, sehingga jumlah film yang ada di bioskoponline.com masih sangat terbatas.

Penelitian ini dimulai dengan pengamatan dan temuan bahwa di laman utama bioskoponline.com terdapat menu lintasan ke media sosial bioskoponline.com, yaitu Instagram, Facebook, Twitter, dan Youtube.Menariknya ketika melihat di Twitter, ternyata ada beberapa praktik yang baru muncul karena terdorong oleh adanya platform baru ini. Pengamatan awal tersebut kemudian memunculkan pertanyaan; satu, bagaimana praktik mediatisasi menonton film melalui bioskoponline.com? dua, mengapa pengguna layanan bioskoponline.com mempraktikkan mediatisasi?

Teori mediatisasi yang disampaikan oleh Krotz (2007) melandasi pertanyaanpertanyaan tersebut yang kemudian berlanjut diantisipasi-perusahaan pada 24 Oktober 2020. 
pada penelitian menggunakan intrinsic case study sebagai metode penelitian. Metode tersebut dipilih karena ketertarikan pada sistem unik yang diterapkan bioskoponline.com.

Penelitian tentang layanan video daring sudah beberapa kali dilakukan, antara lain penelitian berjudul "Analisis Perpektif Regulasi Over The Top di Indonesia dengan Pendekatan Regulatory Impact Analysis"2 dan "Pengembangan Kebijakan Terhadap Penyediaan Layanan Aplikasi dan Konten Pada Ekosistem Digital Melalui Over the Top"3. Kedua penelitian tersebut berfokus pada upaya regulasi terkait layanan video daring. Penelitian lain berjudul "Analisis Faktor-Faktor yang Mempengaruhi Willingness to Subscribe: Telaah Pada Layanan Video On Demand Netflix"4 menunjukkan bahwa layanan video daring legal masih kesulitan berhadapan dengan situs ilegal yang bisa diakses secara gratis.

Pembajakan terhadap karya digital tidak hanya terjadi pada film, tetapi juga musik.

\footnotetext{
${ }^{2}$ Valentine, L.Z. (2018). Analisis Perpektif Regulasi Over The Top di Indonesia dengan Pendekatan Regulatory Impact Analysis. Diakses melalui

https://pdfs.semanticscholar.org/ed61/9ce787e72 05a6a0e90225ff0929daeaf9e75.pdf? ga $=2.6128$ 4076.173264839.16066652351607047972.1606665235 pada 23 Oktober 2020.

${ }^{3}$ Setiawan, A.B. (2018). Pengembangan Kebijakan Terhadap Penyediaan Layanan Aplikasi dan Konten Pada Ekosistem Digital Melalui Over the Top. Diakses melalui https://pdfs.semanticscholar.org/8d7e/f8a36c123
}

Oleh sebab itu, temuan dalam penelitian "Peran Layanan Over-the-top (Ott) pada Konsumen Musik Ilegal"5 dapat dijadikan referensi. Dalam penelitian tersebut, ditemukan peluang pembajakan bisa diatasi dengan penegasan hukum yang menyeluruh dan meningkatkan brand awareness dari layanan legal. Hal tersebut juga ditemukan dalam beberapa postingan terkait bioskoponline.com di Twitter. Maka kemudian, penelitian ini menjadi upaya untuk melihat dan menjelaskan bagaimana praktik yang dilakukan oleh pengguna bioskoponline.com selama menonton film di platform tersebut. Tujuannya untuk mengetahui apa saja hal yang disukai oleh penonton sembari menikmati film Indonesia. Hasil penelitian diharapkan memperkaya pengetahuan tentang audiens, terutama proses menonton film daring agar dapat menjadi sarana pelestarian seni serta budaya Indonesia (dalam hal ini melalui film), serta membangun kesadaran untuk mengapresiasinya secara layak.

8063f60642b4d6688649484f192.pdf pada 23 Oktober 2020.

\footnotetext{
${ }^{4}$ Hasan, V.A. (2017). Analisis Faktor-Faktor yang Mempengaruhi Willingness to Subscribe: Telaah Pada Layanan Video On Demand Netflix. Diakses melalui https://ejournals.umn.ac.id/index.php/manajeme n/article/view/595 pada 23 Oktober 2020.

${ }^{5}$ Putuhena, A.G., dan Irwansyah. (2019). Peran Layanan Over-the-top $(\mathrm{Ott})$ pada Konsumen Musik Ilegal. Diakses melalui https://jurnal.kominfo.go.id/index.php/jskm/artic le/view/2265/1183 pada 23 Oktober 2020.
} 


\section{METODE PENELITIAN}

Metode penelitian menggunakan intrinsic case study. Menggunakan metode tersebut, menurut Stouffer (melalui Stake dalam Denzin dan Lincoln, Yvonna S., 2005:447) terlebih dahulu yang perlu diketahui adalah the nature of the case, sifat khas pada bioskoponline.com, terutama aktivitas dan fungsinya, lalu latar belakang historisnya, settingnya secara fisik, konteks lain seperti ekonomi, politik, legal, dan estetik, kasus lain yang sudah ada untuk mengenali kasus ini, dan dikolaborasikan dengan data dari informan. Data yang didapat kemudian diolah untuk menganalisis isu-isu krusial dalam kasus yang diteliti.

$$
\text { Penelitian dilakukan dengan }
$$
mengamati cuitan (postingan) di Twitter dan wawancara melalui direct message di Twitter dengan dua pengguna bioskoponline.com. Pengguna yang diwawancarai dipilih karena cuitannya menunjukkan aktivitas yang dilakukan sambil menonton dan membahas tentang pembajakan film yang merupakan isu krusial dalam industri perfilman Indonesia.

\section{PEMBAHASAN}

\section{Merayakan Privatisasi}

bioskoponline.com merupakan salah satu layanan untuk menonton film secara daring (transactional video on demand/TVOD), yang biasanya bercirikan kemudahan akses di mana pun dan kapan pun. Menariknya saat awal penelitian ini dilakukan, bioskoponline.com hanya bisa diakses melalui komputer, sehingga ada pembatasan ruang pengguna menikmati tayangan film. Hal tersebut membuat beberapa pengguna memposting harapan agar bioskoponline.com bisa dinikmati melalui smartphone. Menanggapi hal tersebut, pembatasan mulai dihilangkan dengan aksesibilitas melalui browser di smartphone. Meski demikian, menurut Ega, salah satu pengguna bioskoponline.com yang saya wawancarai melalui direct message Twitter, ia memilih menonton melalui komputer (laptop) karena merasa lebih leluasa dalam menonton filmnya bersama pasangan. Berdasarkan postinganpostingan di Twitter terkait bioskoponline.com, terlihat ekspresi kegembiraan penggunanya yang menunjukkan bahwa yang mereka lakukan bukan sekadar menonton film secara daring, melainkan juga mengubah moda menonton yang tadinya secara konvensional di bioskop menjadi daring.

$$
\text { Selama menonton }
$$
di bioskoponline.com, pengguna dapat terus melihat kode yang muncul di tengah layar. Hal tersebut bisa mengganggu kenyamanan dalam menonton, tetapi tidak ditemukan adanya pengguna yang keberatan akan hal tersebut. Mereka memakluminya sebagai salah satu mekanisme yang diterapkan oleh bioskoponline.com untuk menghindari pembajakan. bioskoponline.com telah mensubstitusi bioskop konvensional, karena 
menjadi perpanjangan komunikasi bioskop konvensional dalam kaitannya dengan ruang, waktu, dan cara berekspresi (Schulz melalui Hepp, 2011:3). Meski demikian, moda daring bioskoponline.com juga memunculkan berbagai praktik yang disebut Schulz sebagai amalgamation dalam mediatisasi, yaitu praktik bersamaan yang berkaitan dengan media dan yang tidak.

$$
\text { Menonton film melalui }
$$

bioskoponline.com membuat penggunanya lebih leluasa; tidak perlu mengantre untuk mendapatkan tiket, tidak perlu berdandan seperti ketika akan ke bioskop, tidak ada lagi kekhawatiran karena dilarang membawa makanan atau minuman selama menonton film. Pada gambar 1.1, pengguna dengan nama Rizky di Twitter (username @ rbayuokt) menonton sambil membawa camilan yang bukan dijajakan oleh pihak bioskop. Sementara itu pada gambar 1.2, Ega, pengguna lain dengan username Twitter@meythe3rd@mencuitkan pengalamannya menonton melalui bioskoponline.com sambil makan berat dan minum jahe hangat.

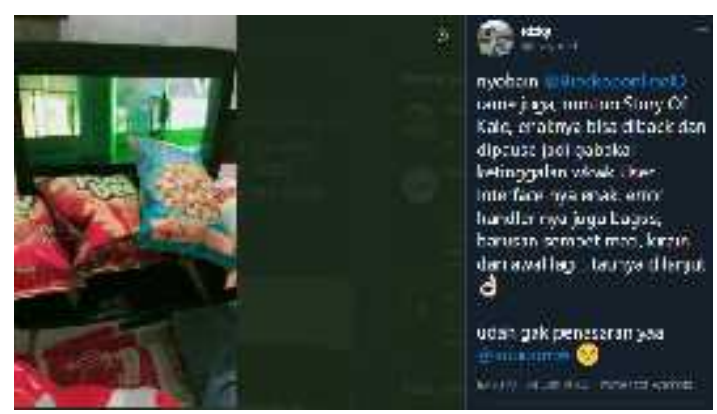

Gambar 1.1. Pengguna mencuitkan keasyikan menonton film melalui bioskoponline.com sambil menunjukkan aneka cemilan sebagai teman menonton.

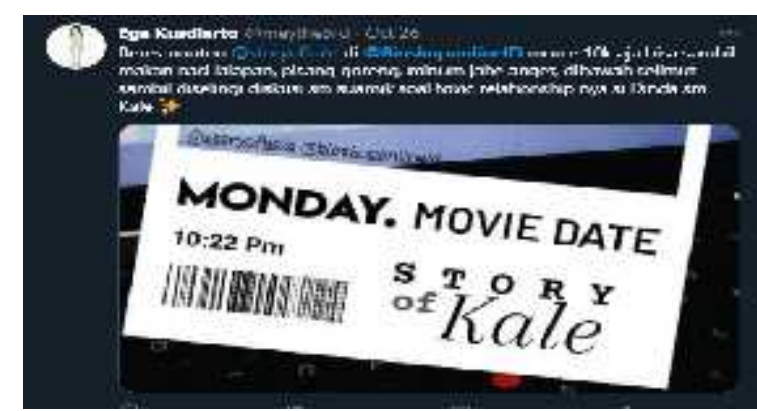

Gambar 1.2. Pengguna mencuitkan murahnya menonton film melalui bioskoponline.com dan berbagai kegiatan yang dilakukannya selama menonton.

Ega menceritakan, ia menonton film di bioskoponline.com bersama suaminya, dan mereka senang bisa leluasa mendiskusikan topik yang diangkat dalam film hingga level yg lebih privat.

"[...] trs bs bebas sambil diskusi soal plot filmnya, topik yg diangkat di film itu yg ttg toxic relationship yg akhirnya berlanjut ke deeptalk sampe ketiduran, hahaha, tanpa ganggu org lain jg, kan kl di bioskop biasanya kita gabole berisik biar ga ganggu org lain gt kan".

Dalam hal ini, menonton film secara daring juga mendukung kebiasaan mendiskusikan film yang lebih intens tanpa harus menunggu film selesai ditonton atau takut mengganggu penonton lain.

Apa yang dilakukan oleh Rizky dan Ega tentu tidak bisa dilakukan jika menonton di bioskop konvensional, karena pihak bioskop hanya membolehkan membawa makanan dan minuman yang dijual di dalam gedung bioskop; biasanya berupa popcorn dan minuman bersoda. Alasan pihak bioskop biasanya adalah demi mencegah polusi suara ketika penonton mengunyah makanan sehingga bisa mengganggu penonton lainnya. Tetapi 


\section{Fina Zahra}

Bioskop Dalam Rumah (Mediatisasi Bioskop)

dengan menonton secara daring di ruang privat masing-masing, pengguna bioskoponline.com bebas memilih makanan dan minuman yang dikonsumsi selama menonton film dan bebas berdiskusi. Bahkan ketika hal tersebut dipamerkan melalui media sosial dengan menyebut akun Twitter bioskoponline.com, tak akan ada teguran.

Sementara itu, pengguna pun bisa memilih menonton dengan santai secara individu maupun bersama-sama. Pada gambar 1.3, terlihat pengguna yang dengan senang hati mengatur secara teknis agar bisa nobar (menonton bareng) di layar yang lebih luas dengan menyambungkannya ke layar televisi. Namun pada gambar 1.4, terlihat pengguna yang menonton santai secara individu menggunakan tablet.

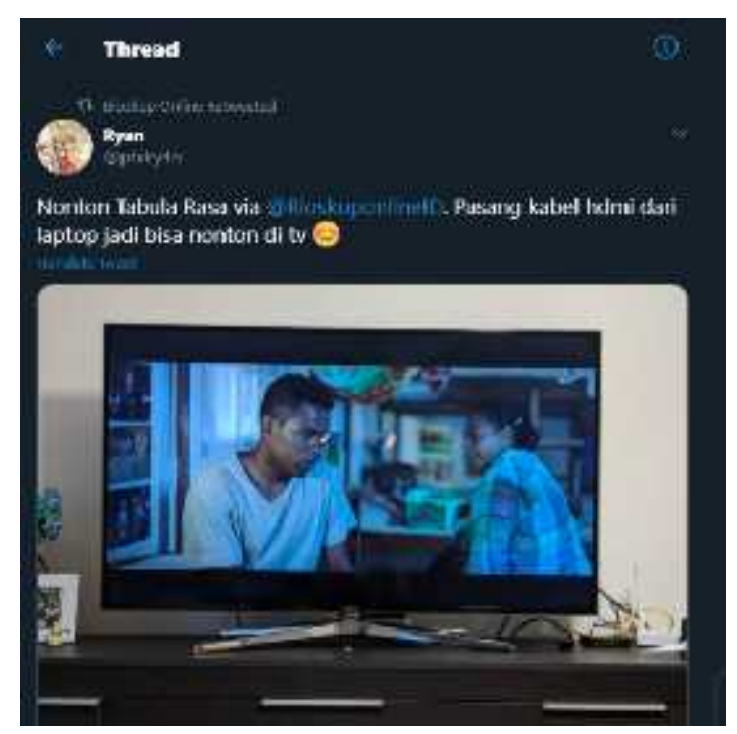

Gambar 1.3. Pengguna menonton melalui layar televisi menggunakan kabel hdmi.

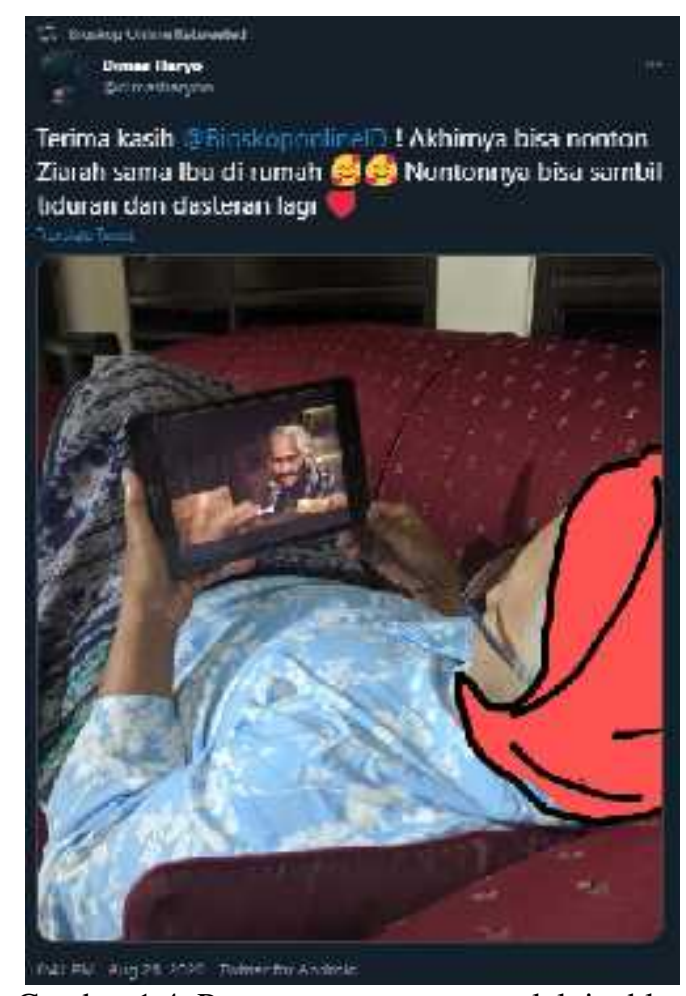

Gambar 1.4. Pengguna menonton melalui tablet.

Hasil penelitian menunjukkan bahwa sembari menonton film secara daring, pengguna melakukan beberapa aktivitas yang tidak bisa dilakukan di bioskop konvensional. Menonton film secara daring menjadi ajang perayaan privatisasi kegiatan yang tadinya dilakukan di ruang publik, karena meski menonton film yang sama, masing-masing pengguna bioskoponline.com bebas menentukan kapan dan bagaimana caranya menikmati film dengan aturan yang lebih longgar daripada ketika menonton di bioskop konvensional.

Rizky pada gambar 1.1 mencuitkan asyiknya menonton melalui bioskoponline.com karena ia bisa mengulang dan menjeda pemutaran film sehingga pasti dapat menonton keseluruhan film. Sementara itu, Ega mengatakan bahwa ia menonton 
Story of Kale berulang kali selama 2 hari berturut-turut (selama sekali pembelian tiket). Pengalaman Rizky dan Ega tersebut sangat berbeda dengan menonton di bioskop konvensional di mana penonton harus menyesuaikan kegiatannya agar bisa menonton film secara utuh. Memang ada beberapa aturan yang diberlakukan oleh bioskoponline.com sebagai penyedia layanan, seperti batasan cara dan waktu mengakses film, serta batasan agar tidak membajak film. Namun, pengguna tidak diatur dalam membawa konsumsi, dan tidak ada jadwal khusus pemutaran film.

\section{Wacana Melawan Pembajakan}

Privatisasi kegiatan yang tadinya dilakukan di ruang publik menjadi daya tarik bioskoponline.com. Namun tidak berhenti di situ, banyaknya postingan yang memperlihatkan aktivitas di ruang privat tersebut menunjukkan bahwa "mengalami" saja tidak cukup, melainkan ada urgensi untuk menampilkan apa yang didapatkan dari menggunakan bioskoponline.com. Ega, informan penelitian ini, mengaku sengaja memposting sebagai wujud apresiasi terhadap bioskoponline.com yang merupakan buatan lokal, sekaligus mempengaruhi orang lain agar ikut menonton.

"Kalo soal bikin status di medsos itu sih selain buat apresiasi bioskop online yg punya lokal (makanya aku tag medsos bioskop online dot com) juga buat ngasi info syukur2 bisa ngeinfluence ke temen $2 \mathrm{ku}$ yg jg doyan nntn film buat ikutan nntn film yg aku tonton".
Mengapresiasi karya lokal menjadi salah satu isu yang banyak diperbincangkan dalam postingan terkait bioskoponline.com. Terlebih lagi, tidak lama dari waktu rilisnya, Story of Kale sudah dibajak dan didistribusikan secara ilegal di salah satu aplikasi chatting populer. Pembajakan karya digital sudah lama menjadi keresahan dalam industri perfilman Indonesia, karena begitu mudah dilakukan dan sulit dibendung. Argumen yang sering mengemuka adalah biaya yang harus dikeluarkan untuk menonton film secara legal terbilang mahal. Dalam wawancara dengan Ega sendiri mengaku berlangganan sejumlah TVOD lain, tetapi sebenarnya merasa berat dengan biaya berlangganannya. Oleh sebab itu, ia senang sekali ketika tahu bahwa biaya menonton di bioskoponline.com terjangkau. Lalu, mengapa Story of Kale yang merupakan film eksklusif bioskoponline.com masih juga dibajak?

Membajak film dan menikmatinya telah menjadi budaya; pemaknaan praktik tersebut sebagai hal yang wajar telah menyebar dan dilestarikan. Maka tak heran meski sudah dilakukan upaya pencegahan seperti sistem pembelian per tiket dan pemberian kode pada tengah layar Story of Kale masih juga dibajak.

Menariknya, sebagaimana terlihat di gambar 1.5, banyak pengguna Twitter yang mengkritik pembajakan terhadap Story of 


\section{Fina Zahra}

Bioskop Dalam Rumah (Mediatisasi Bioskop)

Kale dan mengajak untuk beralih menonton secara legal di bioskoponline.com. Mereka juga menyertakan bukti pembelian yang menunjukkan bahwa menonton di TVOD tersebut harganya terjangkau, sebagai penguat argumen betapa tidak layaknya pembajakan yang terjadi.

\section{Para pengguna bioskoponline.com} melawan pembajakan dalam industri perfilman Indonesia dengan memproduksi pengetahuan bahwa menonton film secara legal di bioskoponline.com terjangkau, atau yang oleh Foucault (melalui Barker, 2004:54) disebut sebagai wacana, menggunakan fotografi sebagai alatnya. Fotografi, menurut Rusli (2016:95), berperan sebagai mediator yang mampu menyampaikan dan mengkomunikasikan kebenaran dan realitas visual tanpa menambah atau mengurangi objek.

Story of Kale menjadi trending topic Twitter selama setidaknya tiga hari berturutturut dengan pembahasan seputar ulasan dan opini terhadap film tersebut serta isu pembajakannya. Hal ini menunjukkan adanya peluang besar untuk melawan pembajakan. Sebagaimana Ega yang terbujuk untuk menonton Story of Kale di bioskoponline.com setelah melihatnya trending topic, maka wacana melawan pembajakan dan membudayakan menonton film secara legal dapat pula diupayakan menggunakan fitur tersebut.

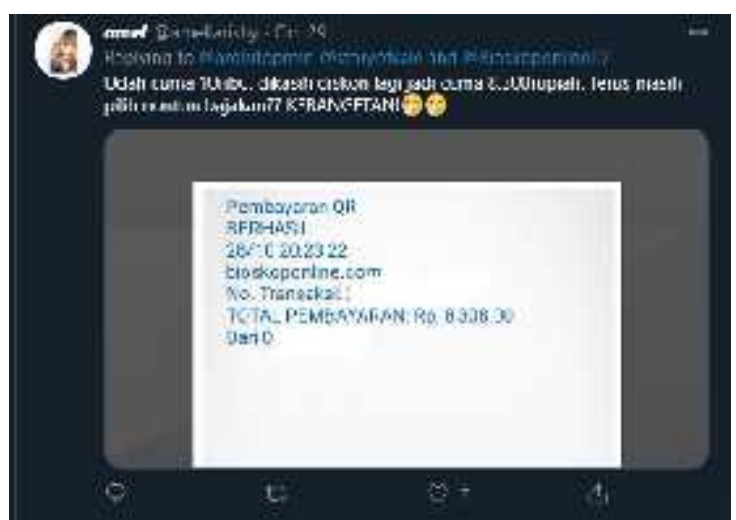

Gambar 1.5. Kritik terhadap pembajakan Story of Kale sambil menunjukkan betapa terjangkaunya menonton secara legal di bioskoponline.com

Postingan para pengguna bioskoponline.com yang sekaligus menyertakan foto bukan sekadar gambaran kesenangan menggunakan layanan tersebut, melainkan juga upaya membuat orang lain merasa familiar dengan situasi tertentu dan termotivasi melakukan hal yang sama. Para pengguna bioskoponline.com termasuk dalam kategori pioneer communities (Hepp, 2016:2), yaitu sekelompok aktor tertentu yang menggerakkan mediatisasi. Hepp berargumen bahwa penggunaan media oleh kelompok tersebut memungkinkan adanya praktik masif yang mana orang lain meniru tindakan kelompok tersebut. Oleh sebab itu, jika kelompok tersebut aktif menyebarluaskan wacana melawan pembajakan, maka pembajakan bisa dikurangi dan menikmati film Indonesia hanya secara legal dapat menjadi budaya baru yang lebih dominan.

\section{KESIMPULAN}

Tindakan para pengguna bioskoponline.com memposting (di Twitter) pengalaman mereka menonton film di TVOD 
tersebut merupakan perayaan akan privatisasi aktivitas yang tadinya dilakukan di ruang publik, sekaligus berwacana melawan pembajakan terhadap film Indonesia. Menariknya, hal tersebut bukan semata karena regulasi yang dibuat oleh pemerintah, TVOD, maupun pihak kerator film, melainkan dari sisi penggunanya. Mereka adalah agen penting dalam wacana melawan pembajakan.

Wacana yang dilakukan oleh para pengguna bioskoponline.com dapat membawa angin segar bagi industri film Indonesia secara keseluruhan, tetapi saat ini belum menjadi wacana utama, karena wacana yang mewajarkan pembajakan masih dominan. Oleh sebab itu, sudah selayaknya bioskoponline.com merespon secara cepat dan tepat agar wacana melawan pembajakan ini dapat menjadi wacana utama dan membudaya, sehingga film Indonesia mendapatkan apresiasi sebagaimana mestinya. Berdasarkan hasil penelitian, penguatan basis komunitas para pengguna TVOD tersebut dinilai sangat penting dilakukan oleh bioskoponline.com.

\section{KEPUSTAKAAN}

\section{Artikel Jurnal}

Hasan, V.A. (2017). Analisis Faktor-Faktor yang Mempengaruhi Willingness to Subscribe: Telaah Pada Layanan Video on Demand Netflix. Ultima Management: Jurnal Ilmu Manajemen, Vol. 9 (1), 22-38.

Putuhena, A.G., dan Irwansyah. (2019). Peran Layanan Over-the-top (Ott) pada
Konsumen Musik Ilegal. Jurnal Studi Komunikasi dan Media, Vol. 23, No.2, 167-180.

Rusli, Edial. (2016). Imajinasi Ke Imajinasi Visual Fotografi. Rekam: Jurnal Fotografi, Televisi, Animasi, Vol. 12, No. 2, 91-105.

Setiawan, A.B. (2018). Pengembangan Kebijakan Terhadap Penyediaan Layanan Aplikasi dan Konten Pada Ekosistem Digital Melalui Over the Top. Jurnal Penelitian Pos dan Informatika, Vol. 8, No. 2, 169 - 185.

Valentine, L.Z. (2018). Analisis Perpektif Regulasi Over the Top di Indonesia dengan Pendekatan Regulatory Impact Analysis. InComTech: Jurnal Telekomunikasi dan Komputer, Vol. 8, No. 3, 222-232.

\section{Buku}

Barker, Chris. (2004). The Sage Dictionary of Cultural Studies. London \& Thousand Oaks, \& New Delhi: Sage Publications.

\section{Bunga Rampai}

Stake, Robert E. (2005). Qualitative Case Studies. Dalam Denzin, Norman K. (Editor) dan Lincoln, Yvonna S. (Editors). The Sage Handbook of Qualitative Research (Third Edition) (h. 443-466). Thousand Oaks: Sage Publications Inc.

\section{Informan}

Ega (username Twitter @ meythe3rd). (2020). Pengguna bioskoponline.com.

Rizky (username Twitter@ @rbayuokt). (2020). Pengguna bioskoponline.com yang berprofesi sebagai ux operator.

\section{Pustaka Laman}

Hepp, Andreas. (2011). Mediatization, Media Technologies and the 'Moulding F orces' of the Media. The International Communication Association's 2011 Virtual Conference (23 May-10 June). Diakses melalui https://www.researchgate.net/publicatio 


\section{Fina Zahra}

Bioskop Dalam Rumah (Mediatisasi Bioskop)

n/276202928_Mediatization_and_the ' molding_force'_of the media.

Hepp, Andreas. (2016). Pioneer Communities: Collective Actors in Deep Mediatisation. Diakses melalui https://www.researchgate.net/publicatio n/307475370_Pioneer_communities_co llective_actors_in_deep_mediatisation.

Julian, M. (2020). McKinsey: Begini Kebiasaan Baru Konsumen yang Perlu Diantisipasi Perusahaan. Diakses melalui

https://internasional.kontan.co.id/news/ mckinsey-begini-kebiasaan-baru-

konsumen-yang-perlu-diantisipasiperusahaan pada 24 Oktober 2020.

Krotz F. (2007) The Meta-Process of Mediatization as a Conceptual Frame.

Diakses melalui

https://www.researchgate.net/publication/24 0717512_The Meta-

Process_of_'Mediatization'_as_a_Conceptua 1_Frame pada 23 Oktober 2020. 